\title{
The Results of Physiotherapy in Leprosy Patients with Early Paralysis*
}

\author{
K. B. KOTHARE \\ Physiotherapist, Acworth Leprosy Hospital, Wadala, Bombay 31, India
}

\begin{abstract}
A total of 142 patients who had suffered from different types of leprosy (having, in all, 180 nerve lesions) were given physiotherapy. The majority of them, irrespective of the type of leprosy, improved markedly from regular physiotherapy, and the benefits persisted after treatment had stopped. The improvement was much less marked when therapy was irregular.
\end{abstract}

\section{Introduction}

A perusal of the literature on physiotherapy in leprosy reveals much information on techniques, appliances and equipment. In comparison, detailed analyses of the results of physiotherapy are scanty. In the present study an attempt has been made to determine the extent of recovery and maintenance of muscle function in patients with early paralysis.

\section{Materials and Methods}

A total of 142 patients with some muscle paralysis of less than 3 months' duration were selected for physiotherapeutic treatment; all of them had either isolated or combined nerve damage affecting 180 principal peripheral trunks. All were assessed clinically and electrically both before and after treatment, and then followed up. The treatment was given daily for 3 to 6 months.

Evaluation of muscle power, based on the International Scale, was combined with an assessment of nerve function, to give a scale of I to IV in order of increasing severity of damage. Two patients showed neuropraxic lesions-clinical paralysis, and no electrical evidence of degeneration.

The physiotherapeutic procedures adopted were as follows: prevention of deformity (by splinting); encouragement of function (by active exercises); maintenance of full range of joint movements (by passive exercises); maintenance of good circulation (by wax baths and oil massage); and prevention of muscle atrophy (by electrical stimulation).

\section{Results}

Table 1 gives details of the number of patients assessed before treatment and the improvement or deterioration observed.

* Approved for publication January, 1972. 
TABLE 1

\begin{tabular}{|c|c|c|c|c|c|c|}
\hline \multirow{2}{*}{$\begin{array}{l}\text { Grade before } \\
\text { treatment }\end{array}$} & \multirow{2}{*}{$\begin{array}{c}\text { Total no. of } \\
\text { nerve lesions }\end{array}$} & \multicolumn{5}{|c|}{ Grades after treatment } \\
\hline & & 0 & I & II & III & IV \\
\hline 0 & 2 & 2 & - & - & - & \\
\hline I & 10 & 7 & - & - & - & 3 \\
\hline II & 109 & 33 & 3 & - & - & 73 \\
\hline III & 59 & 9 & 26 & 4 & - & 20 \\
\hline Total & 180 & 51 & 29 & 4 & - & 96 \\
\hline
\end{tabular}

To determine the reason why patients with early lesions deteriorated ( 3 with Grade-I and 73 with Grade-II lesions) these cases were further analysed, with the results shown in Table 2.

TABLE 2

\begin{tabular}{|c|c|c|c|c|c|c|c|c|}
\hline \multirow{3}{*}{$\begin{array}{l}\text { Grade before } \\
\text { treatment }\end{array}$} & \multirow{3}{*}{$\begin{array}{l}\text { Type of } \\
\text { leprosy }\end{array}$} & \multirow{3}{*}{$\begin{array}{l}\text { No. of } \\
\text { patients }\end{array}$} & \multicolumn{5}{|c|}{ Treatment } & \\
\hline & & & \multicolumn{3}{|c|}{ Regular } & \multicolumn{3}{|c|}{ Irregular } \\
\hline & & & Impr. & Unimpr. & Total & Impr. & Unimpr. & Total \\
\hline \multirow[t]{4}{*}{ I } & $\mathrm{T}$ & 10 & 7 & - & 7 & - & 3 & 3 \\
\hline & I & - & - & - & - & - & - & - \\
\hline & $\mathrm{L}$ & - & - & - & - & - & - & - \\
\hline & & 10 & 7 & - & 7 & - & 3 & 3 \\
\hline \multirow[t]{4}{*}{ II } & $\mathrm{T}$ & 95 & 26 & 2 & 28 & 5 & 62 & 67 \\
\hline & I & 6 & 2 & - & 2 & - & 4 & 4 \\
\hline & L & 8 & 3 & - & 3 & - & 5 & 5 \\
\hline & & 109 & 31 & 2 & 33 & 5 & 71 & 76 \\
\hline
\end{tabular}

$\mathrm{T}$, tuberculoid; I, indeterminate; L, lepromatous.

It would appear that the sole reason for failure to improve in the case of the 3 patients originally classed as Grade I lay in the fact that they were irregular in following the treatment offered. But among the patients in Grade II, 2 did not recover in spite of regular treatment, while 5 of those whose treatment was irregular recovered. The 59 patients in Grade III are similarly analysed with respect to regular and irregular treatment, with the results as shown in Table 3.

TABLE 3

\begin{tabular}{|c|c|c|c|c|c|c|c|}
\hline \multirow{2}{*}{$\begin{array}{l}\text { Grade before } \\
\text { treatment }\end{array}$} & \multirow{2}{*}{$\begin{array}{l}\text { Type of } \\
\text { leprosy }\end{array}$} & \multicolumn{3}{|c|}{ Regular } & \multicolumn{3}{|c|}{ Irregular } \\
\hline & & Impr. & Unimpr. & Total & Impr. & Unimpr. & Total \\
\hline \multirow{4}{*}{ III } & $\mathrm{T}$ & 30 & 1 & 31 & 2 & 15 & 17 \\
\hline & I & 7 & - & 7 & - & - & - \\
\hline & L & - & - & - & - & 4 & 4 \\
\hline & & 37 & 1 & 38 & 2 & 19 & 21 \\
\hline
\end{tabular}


The majority of patients whose original assessment was Grade III showed some degree of improvement: 39 lesions out of 59.

From among the 84 patients who had improved and had ceased having physiotherapy, 26 were seen again after 2 years. In only 3 of them was the improvement not maintained. It would seem that physiotherapy is of benefit not only temporarily, or for as long as it is continued, but also for a variable time afterwards.

\section{Acknowledgements}

I thank Dr N. Figueredo, Ex-Special Officer, Acworth Leprosy Hospital, for valuable guidance, and Dr N. D. Katdare, Superintendent, Acworth Leprosy Hospital, for permission to use the hospital records and for his helpful suggestions. I also wish to thank Dr (Mrs) S. S. Pandya (Tata Department of Plastic Surgery, J.J. Group of Hospitals, Bombay) for her help in the preparation of this paper. 